\title{
Building and Breaking Discursive Conventions in Academic Writing ${ }^{1}$
}

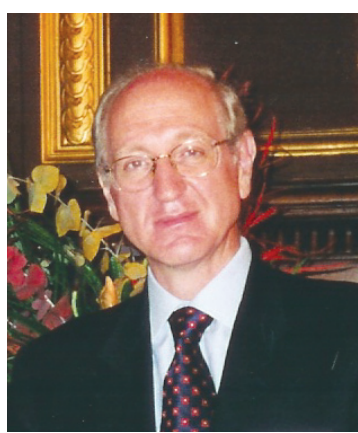

Maurizio Gotti

\section{Introduction}

A cademic discourse cannot be seen as a single, monolithic entity. Recent research (e.g. Crammond 1998; Hyland 2000) clearly indicates that academic writing is not a uniform body of discourse but varies according to disciplinary conventions, cultural expectations and writers' professional status and experience. Moreover academic communication has proved to be a very interactive and dynamic field. Although different academic discourses have specific generic characteristics (Swales 1990; Bhatia 1993), they also allow writers a certain degree of flexibility. At the same time, academic genres themselves are not stable but highly dynamic and tightly related to their socio-professional contexts (Bhatia 2004; Swales 2004, Bhatia, Gotti 2006). Studies that investigate academic writing have shown that textual differences are clearly part of the strategic and creative choices made by the authors to attain their rhetorical objectives.

In order to be accepted by their academic community, scholars need to be aware of the practices commonly used in general expository academic prose. Such constraints interact with the evident pressures of individual identities, thus complicating the overall picture. Indeed, writers sometimes employ differences in the wording of their texts to mark their own identity. Despite the standardising pressure of cultural and language-related factors, academic communication remains in many ways a highly personal affair, with active participation in a disciplinary community requiring a multidimensional discourse that combines the professional, institutional, social and individual identities of its members.

The concept of identity itself remains somewhat elusive and contested. As it is mainly established through public discourse, identity has a double orientation, both towards commonality as well as individuality. Indeed, identity itself is a matter of individuality as well as sameness: it defines what makes individuals similar to their peers but also what makes them to a certain extent unique. Academics need to fulfil a double requirement: achieve credibility as disciplinary members and official recognition as individual innovators. Negotiating an autonomous representation of self diverging from the standardizing conventions of disciplinary communication, however, requires consummate skills and extensive experience on the part of the academic.

Research on specialised discourse has recently underlined the important roles played by an author's argumentative production in the creation of his academic identity (Cherry 1988; Hatch et al. 1993; Ivanič 1998). The analysis of the linguistic choices made by authors in their texts is often able to identify the hidden processes of cognition that lie beneath the active construction of argumentative discourse. It makes explicit the hidden self lurking behind the author's words and show how identity is created in a given con- 
text and how it is conveyed to the other members of the community. This constructionist perspective places an emphasis on discourse as the means through which the self manifests itself to the world: it is how we claim or resist membership of our social groups to define who we are in relation to others, not only employing, but sometimes transforming existing discourses (Bakhtin 1986). By presenting themselves in alignment or dissonance with previous writings, writers consciously take up the identity options that are available, creating their own niche in the specialised community to which they belong.

This process of identity construction thus implies a confrontation of the author with both existing norms and personal traits. In presenting his argumentative line the academic is faced with a choice: either follow the traditional path of shared conventions or assert his innovative role by emphasising what makes his message appear unique. In order to be valued by colleagues, authors often make use of the means that disciplinary communities make available. The effective shaping of a writer's identity crucially depends on his adoption of shared and recognizable routine responses to specific professional tasks. This does not mean that these conventions are fixed and monolithic as they change over time in response to changing circumstances, but that discursive innovations emerge slowly and disciplinary conventions are a valued symbolic resource in identity construction.

Also the concept of discipline is elusive since, like most communities, disciplines experience constant change, also due to pressure by institutional and commercial forces as well as intellectual ones. Recently the concept has been contested by post-modernism, which has pointed out fragmentation and the collapse of disciplinary coherence on several occasions. Indeed, disciplines are of course internally diverse, and transdisciplinary relations are commonly established between particular frameworks, approaches, theories within the disciplines involved. Moreover, new disciplines continue to spring up, usually at the intersections of existing ones, while some traditional ones decline and sometimes disappear. These changes do not occur in a vacuum but derive from communitybased orientations which give rise to new 'voices' closely associated with those particular fields of study. However, these new academic conventions do not merely form a closed and determining system, but also enable writers to actively and publicly accomplish an identity through individual discourse choices. Thus, even in the new disciplines there is potential for innovation as well as reproduction in the use of academic discourse.

However, the power to exploit language options and bend the rules is predominantly in the hands of established figures in the disciplines rather than of novices. As they can draw on their disciplinary expertise and rely on their seniority and celebrity in the field, these leading figures are freer to assert autonomous positions, express their own distinctive identity and redefine conventional rhetorical boundaries. An analysis of the literature in this area suggests that it is this kind of authors who are not only linguistically or culturally prone to write in a given way, but who use their competence and creativity to produce highly complex, personalized discourses. In order to achieve their communicative goals and comply with contextual constraints, these authors normally modulate their stylistic choices, adopting more or less formal registers, a more narrative or argumentative style, a more subjective or objective viewpoint, and more personal or impersonal involvement in a variously direct or indirect argumentative line. 


\section{Establishing discursive conventions}

The first part of this paper will take into consideration a period in which new discursive conventions were established to respond to the communicative needs of a discourse community. In particular, it will examine the role of a specific author in this standardising action. The period taken into consideration is the $17^{\text {th }}$ century, the place is England, the discourse community is that of the members of the Royal Society and the author is Robert Boyle. This British scientist has been selected as a paradigmatic figure because of his specific metatextual indications and his many practical exemplifications concerning the new stylistic approach envisaged by the specialised discourse community of that time. Indeed, the influence of Boyle on the formation of these new linguistic conventions has been widely acknowledged by contemporary and subsequent scientists and critics. Boas Hall asserts: "[Boyle] not only described experiments, he taught the world how to write up experiments so that they could readily be repeated" (Hall 1965:43). In particular, attention will be paid to a comprehensive understanding of the interactions between the new conventions and their context, focusing not only on their content and syntactic aspects but also on how new genres were constructed, interpreted and used in the achievement of the specific needs and requirements of the community of practice (Lave, Wenger 1991) that prompted their appearance, and the links established by these new genres between the discursive practices of the members of this community and their research practices. This approach is in line with the recent evolution of genre analysis, as in the latest approaches emphasis on text and context have been almost reversed (cf. Swales 1998; Bhatia 2004), with context attracting more serious attention - though without undermining the importance of linguistic form - in the description of specialised genres.

\subsection{The context}

Among the many developments that took place in $17^{\text {th }}$-century England, a fundamental role was played by the evolution of specialised discourse, which was consequential to the great epistemological and methodological innovations of that period (Vickers 1987; Hunter 1989, Jardine 1999; Shapiro 2000). Indeed, these innovations determined the need for corresponding changes both as regards the methods of communicating information about new scientific discoveries and as regards the most suitable means of expression chosen to describe and discuss the new phenomena then being observed and analysed. This new perspective determined a growth not only in movements whose aim was a reform of the existing verbal code in order to limit its inaccuracy and increase its power of expression, but also in those concerned with the creation of novel expository genres able to guarantee the prompt and widespread diffusion of information relating to the new developments in the various specialised fields. Indeed, this need could no longer be satisfied by the more traditional genres, as the latter mainly followed principles and employed techniques of a prevalently literary type. Moreover, there was a need to socialize the discoveries made and the new ideas developed, also thanks to a collaborative spir- 
it which inspired $17^{\text {th }}$-century specialists, in contrast to the individualism that characterised philosophers in the Renaissance period. The development of the sciences was now seen as a result of public discussion and knowledge sharing, in the conviction that "In Assemblies, the Wits of most men are sharper, their apprehensions readier, their thoughts fuller, than in their closets" (Sprat 1667:98).

The innovative characteristics of this new type of discourse derived from the great importance attributed to the experimental process in the research programmes of Early Modern English men of science, who - elaborating on Francis Bacon's intuitions - shared the principle that the progress of knowledge could not be based on the servile observance of traditional theory, but should rely on the observation of natural phenomena and accurate experimental activity. In particular, this was the attitude taken by the large group of scientists who in the $17^{\text {th }}$ century promoted the formation of the Royal Society. In their preliminary meeting on $28^{\text {th }}$ November 1660 the founders of the Royal Society determined that the purpose of their gathering was "a designe of founding a Colledge for the promoting of Physico-Mathematicall Experimentall Learning" (quoted in Boas Hall 1991:9), and chose the phrase Nullius in verba ('On the words of no one') as their motto. These new researchers emphasized the need for an experimental approach, so as to collect abundant data from which correct generalizations could be derived.

Apart from this emphasis on experimental activity, another important aspect of the new scientific approach consisted in the need for both the procedures and the results of these experiments to be made known to the entire learned world. Indeed, the new scientific community firmly believed that they must differentiate themselves from that of preceding practitioners not only in their new experimental approach, but also by means of the adoption of more appropriate and innovative stylistic choices. Criticism was made both of how language was employed in the various processes of scientific research and, in particular, of the suitability of the tool itself for an accurate, precise expression of the concepts reported. There should be a strict relationship between the observational process and its representation, and a direct link should be established between reality observed and verbal expression. Moreover, the style should be clear and simple in order to make the text more comprehensible.

To carry out their communicative task, scientists needed new expository forms. Already Bacon, by means of the aphorism, had tried out a writing device different from the traditional ones to convey personal observations relating to short and specific items. The other main forms available to the scientist were the essay, the dialogue and the treatise. The first, however, had been used also for literary or philosophical purposes, and therefore retained some rhetorical features unsuitable for scientific purposes. The latter two were more suitable for lengthy issues and, when the purpose was mainly argumentative, would be used in such cases as when a new theory was to be set out or old ones debated. There was a need, instead, for a shorter form, which would offer the scientist the opportunity to report briefly experiments carried out, procedures followed, results obtained, and any personal comments. This genre would allow immediacy of communication, and would protect the writer from any accusation of incomplete theoretical exposition, as its purpose would be mainly descriptive rather than argumentative. The means of communication identified as appropri- 
ate for specialised purposes was the experimental essay, meant to enable the researcher to report his experiences with immediacy and precision. Such a genre, however, would differ from the traditional essay, following foreign models such as Montaigne's, structured on principles inspired either by literary or argumentative criteria.

The main function of the experimental essays was informative, as they were principally written to circulate information about research being carried out in Britain and in other parts of the world. Experiments were usually reported very fully, and even the slightest detail was described, as this would enable the reader to carry out an accurate evaluation of the contents of the essay. Indeed, a feature of experimental essays that immediately strikes the reader is the richness of detail to be found in them. Descriptions were vivid, with an abundance of data providing a precise and immediate representation of the experience reported.

The abundance of detail and the precision of the narration of the experimental events may be attributed to the writer's willingness to provide his readers with as many opportunities as possible to understand his report clearly, not only in order to enable them to come to appropriate conclusions, but also to repeat the same experiment in their own laboratories, and thus prove his results to be more reliable. Indeed, the minuteness of detail and the accuracy of the narration was meant to make repeatability easier and thus encourage the growth of empirical practice in the community of scientists. This emphasis on the promotional purpose of the experimenter's writings betrays the strong feeling of belonging to the new scientific community which animated the members of the Royal Society.

A further reason that justifies the experimenter's recourse to this detailed narrative technique was his need to acquire official recognition of his results. The detailed and accurate description of his personal scientific experience was considered one of the requisites for transforming a personal account into an official protocol to be submitted to the broad community of men of science. The careful and objective narration of one's experiments could provide the materials for proper scrutiny and reliable judgement, and thus permit the transformation of personal results into facts widely accepted by the scientific world. Having obtained in this way the consensus of a wider public, experimental data could become 'matters of fact' and part of scientists' shared culture.

\subsection{Main discursive features of specialised communication in the $17^{\text {th }}$ century}

$17^{\text {th }}$-century natural philosophers were not simply interested in widening the community of scientists among the nobler minds of the period, but also clearly perceived that the causes of differentiation of this group from that of practitioners was not merely methodological and conceptual, but also linguistic and stylistic. Therefore, a gentleman was expected to structure his discourse in an appropriate manner, not only to guarantee a more successful perlocutionary result for his own argumentative text, but also because in that way he could facilitate his interlocutors' interpretative task. As successful argumentative activity implied the need for people to judge the validity of the various issues, it was very important that the language used in discussions should be clear and readily comprehensible. 


\subsubsection{Civility}

In the expression of criticism the tone was usually humble and polite, in line with the features of a 'civil' style. An important reason for the use of this 'civil' style is the fact that the members of this community knew each other either directly or indirectly. This higher degree of cooperation and esteem was reflected in the frequent use of positive adjectives referring to personal qualities such as celebrated, expert, great, industrious, ingenious, learned, worthy. The rules of politeness, however, did not prevent people from expressing themselves freely. Indeed, errors or omissions were pointed out clearly, and motivations and explanations for challenged views were requested from the other party. However, even in the most polemic controversies, the tone remained 'civil' and criticism was expressed in an objective way, avoiding a direct attack on the opponent. Indeed, the 'civility' corresponding to a real gentleman's discourse implied the adoption of a fair attitude towards his interlocutors, and respect for the people whose opinions he was arguing against. This behaviour was meant to follow the rules typical of polite conversation among gentlemen, according to which participants speak in an appropriate way, paying compliments even to the people they are disagreeing with. This respectful and cooperative attitude is also one of the features which Sprat points out as typical of the behaviour of the members of the Royal Society: "They could not be much exasperated one against another in their disagreements, because they acknowledge, that there may be several methods of nature, in producing the same thing, and all equally good." (Sprat 1667/1959:92)

What distinguished a gentleman's behaviour, therefore, was his respect for the person whose views he was criticising and his limiting his objections to the points he saw as incorrect without any unfair recourse to excessive aggressiveness. According to this criterion, ad hominem argument was considered unacceptable, as criticism should be directed towards the issue under debate rather than the opponent(s). On this subject Boyle writes: "For I love to speak of persons with civility, though of things with freedom" (Boyle 1772/1965, 1:312). The civility of a scientist's behaviour could also be seen from the way in which, even when objecting to a certain methodological supposition, he was grateful to the person who expressed it. Indeed, in the course of the discussion the contestants kept repeating that the purpose of their objections was to clarify their own positions and not simply to quarrel. This objective way of analyzing other scientists' conclusions and attacking wrong or inconsistent ideas allowed the argumentative paper to be accepted more readily and highlighted its persuasive strength, thus increasing its perlocutionary effect, which consisted in convincing the reader of the validity of the writer's thesis.

\subsubsection{Conciseness}

The principle of economy of discourse was often pointed out by specialists. Sentences should be as concise as possible with no space given to unnecessary details. In fact, Article IV of Chapter V of the Statutes of the Royal Society (1728) reads: 
In all Reports of Experiments to be brought into the Society, the Matter of Fact shall be barely stated, without any Prefaces, Apologies, or Rhetorical Flourishes, and entered so into the Register-Book, by order of the Society.

However, the criterion of conciseness was subordinate to the higher principle of clarity of exposition, which was considered the most important in terms of perlocutionary value. Indeed, the principle of the avoidance of verbosity so often maintained by the members of the Royal Society was neglected whenever the author ran the risk of being too brief and therefore unclear.

\subsubsection{Objectivity}

Another stylistic feature of the new discursive practice was objectivity: data were to be reported as they were observed, without the writer being required to accompany them with hypotheses or comments. This allowed the researcher to report all the details of his experimental activity, even those that he might not be able to explain, thus reducing his theoretical responsibilities and the risk of being criticized, as "having for the most part the liberty to leave off when he pleases, is not obliged to take upon him to teach others what himself does not understand" (Boyle 1772/1965, 1:303). Experimental accounts, however, provided the identification of useful superstructures on which other scientists might be able to erect appropriate theories. The same principle enabled writers to report also experiments that had been unsuccessful, as the analysis of these experiences might help the reader not to make the same mistakes as those reported or could enable him to draw interesting conclusions.

This stylistic quality also required the researcher to report events faithfully and sincerely, and to express his opinions and conclusions with the degree of positiveness corresponding to the certainty of the facts described. This careful attitude prompted the author to use the various modal expressions that English offered to suit the different degrees of certainty of the facts reported and to adopt verbs like to seem and to appear to report with caution the actions as he perceived them, as can be seen in the following quotation:

(1) His body seemed to be perpendicular to the horizon. [...] We perceived him to lie stark dead with his belly upwards. [...] The other frog [...] seemed to be distressed. [...] She appeared to be very much disquieted. (Boyle 1772/1965 3:359)

The same prudence is shown by hedging expressions, usually placed in parentheses:

(2) The frog was perfectly alive, and continued to appear so (if I am not mistaken) near an hour. (Boyle 1772/1965 3:359)

In taking this cautious attitude, the experimenter not only showed his professional correctness in that he reported actions as he perceived them with the appropriate degree 
of certainty, but offered a picture of himself as a reliable and faithful witness to the events that he was reporting. This stylistic innovation underlines parallel changes in coding conventions: while scholastic writings relied on authorities and reflected absolute certainty with prescriptive impersonal constructions and deontic modality, the empiric approach typical of Royal Society texts implied the adoption of a cautious and tentative attitude to new findings, characterised by subjective epistemic judgements, carefully discussing the possible implications of the researcher's observations.

Another important principle followed in the writing of experimental essays was to reproduce in that activity the same distinction correctly adopted by the scientist between the setting out of the facts observed and his considerations on them. Indeed, Boyle suggests leaving 'a conspicuous interval' (Boyle 1772/1965, 1:2) on the page between the two textual parts (report of experimental findings and reflections on them) so as to show the methodological procedure adopted while underlining the rhetorical and pragmatic difference between those two parts.

\subsubsection{Perspicuity}

As regards the way specialised texts should be written, the prevailing opinion was that authors should adopt a 'philosophical' rather than a 'rhetorical' style - that is, a style which would not coincide with the traditional way of writing, typical of literary and philosophical works. Underlining a need widely felt by the contemporary world of science, Boyle stressed the fact that the expressions used in experimental writings should be 'rather clear and significant, than curiously adorned' (Boyle 1772/1965, 1:304). This choice of a more referential language was due to the very function of specialised works, which was to provide information in as clear a way as possible. This was the reason why in several scientific texts of this period we find a strong condemnation of metaphors, which were usually seen as deceitful devices. The scientific community was convinced that the use of unnecessary rhetorical devices in specialised literature could hinder the comprehensibility of the text.

Boyle also condemned the habit that certain scientists had of using cryptic language so as not to make their discoveries comprehensible to their readers. He maintained, on the contrary, that all works should be written in clear language so that everybody could decode the contents and thus improve their knowledge of the subject. This universal sharing of single discoveries was considered essential for the formation of a specialist community and for the progress of scientific thought. This is the reason why the use of ambiguous terminology was considered unacceptable, as it was perceived as a serious obstacle to correct argumentation which could render communication among scientists impossible. This terminological issue was central to scientific procedures, as the obscure use of language on the writers' part would not only prevent their being understood, but also their being fully accepted into the scientific community. Indeed, criticism of ambiguous language was commonly conveyed in very strong terms, and was often expressed in the metaphorical equivalence between obscurity and falseness. 


\subsubsection{Simplicity of form}

Another feature of the language meant to guarantee maximum comprehension was the adoption of a plain style, making use of simple verb-forms and sentence-constructions. Indeed, the voice commonly used in experimental essays was active, often putting the researcher in a thematic position and usually conferring on it the grammatical function of the subject, so as to parallel his active role in the experimental activity:

(3) We provided a clear round glass [...]. We conveyed the glass [...]. (Boyle 1772/1965 3:362)

The active presence of the scientist was emphasized not only when he was performing some operation, but also when he was observing phenomena or drawing interesting conclusions from his research activity. Evidentiality (Chafe, Nichols 1986) was usually attained by means of observation and perception, two processes which were deemed basic and preliminary to induction (Taavitsainen 2001). The actions regarding observation and perception were usually expressed by verbs having a first person pronoun subject:

(4) I perceived some little motions, which made me conclude him alive. (Boyle 1772/1965 3:360)

Although the active voice was quantitatively prevalent in the narration, there was also appropriate use of the passive. This form was usually employed for specific cases, such as to underline unexpected results or in reporting how certain procedures (usually involving the utilization of equipment) had been carried out. The shift from the active to the passive voice in these cases underlined the passing from the active role of narration of events to the description of procedures that were becoming standardized in the experimenter's repertoire or in that of scientists in general.

The simplicity of form of experimental accounts was also favoured by their temporal structure typical of a narrative text, which was often marked by a series of dates. Here is an example:

(5) An Experiment To examine, what Figure, and Celerity of Motion begetteth, or encreaseth Light and Flame.

This was communicated by Dr Beale, as follows: May 5. 1665. [...] May 6 [...] But on the next Munday (May 8). evening [...] On Tuesday night (May 9) [...] And May 10. [...] (Beale 1666: PT I, 13 226-227)

\subsubsection{The explicitness of the argumentative structure}

The new stylistic approach also implied the adoption of a more accurate expository technique. In Boyle's opinion, "principles ought to be like diamonds, as well very clear, 
as perfectly solid" (Boyle 1772/1965 1:471). Therefore, it was a natural philosopher's duty to structure his discourse in an appropriate manner, not only to guarantee a more successful perlocutionary result for his own argumentative text, but also because in that way he could facilitate his interlocutors' interpretative task. This is the reason why very frequently, in dealing with a theoretical point, the author emphasized the structure of his reasoning by means of appropriate comments such as the following:

(6) To proceed then to my propositions, I shall begin with this, that (Prop. I.) It seems not absurd to conceive, that [...].

But (continues Carneades) presuming, that the first proposition needs not be longer insisted on, I will pass on to the second, and tell you that (Prop. II.) Neither it is impossible that [...].

But to proceed to a new proposition

(Prop. III.) I shall not peremptorily deny, that [ ...].

To these three concessions, I have but this fourth to add, that

(Prop. IV.) It may likewise be granted, that [...].

(Boyle 1772/1965 1:474-7)

After outlining the structure of his argumentation, the author proceeded to develop it, carefully preceding each step of his reasoning with transparent metatextual statements:

(7) That I may not make this paradox a greater than needs must, I will first briefly explain what the proposition means, before I proceed to argue for it. [...] That then, which I mean by the proposition I am explaining is, that [...]. Having thus explained my proposition, I shall endeavour to do two things, to prove it; the first of which is to shew, that [...]. And the other is to make it probable, that [...]. To begin then with the first of these, I consider, that [...]. (Boyle 1772/1965 1:493)

\subsection{The popularity of the new discursive criteria}

The wide dissemination of scientific communication that took place in the $17^{\text {th }}$ century thus served a stylistic purpose, as the metatextual considerations expressed in these texts helped the creation of new discursive practices. The publication of experimental essays did not only contribute to the advancement of specialised disciplines as it favoured the establishment of a common empirical and methodological approach, but also promoted the creation of new patterns of scientific communication. These new discursive conventions soon became a standard model for the research community that was greatly expanding and becoming consolidated in England in that period. The rapid diffusion of scientific journals made them established criteria commonly followed by men of science. In the course of time these stylistic norms certainly evolved and became more welldefined. Important changes have also taken place, such as a shift from an 'author-centred' to an 'object-centred' rhetoric, expressed linguistically in more-or-less 'involved' 
and 'verbal' terms (Atkinson 1999). From the syntactic point of view, the centuries following the $17^{\text {th }}$ have developed and consolidated the features present in early scientific communication, with an increase in the processes of nominalization and premodification of specialised discourse. However, many of its early features have remained and testify to the seminal role played by the reflections and writing practices introduced by Boyle and his contemporaries.

\section{Aspects of Individuality in J.M. Keynes's General Theory}

This section will explore authorial identity in the publications of a highly successful scholar (John Maynard Keynes) in order to show how such a leading academic has managed the tension between shared norms and individual preferences, not only to contribute to the authority of the former but especially to assert his own creativity through innovative textual practices.

John Maynard Keynes was certainly the single most influential economist of the twentieth century. As the son of a Cambridge economist and logician (John Neville Keynes), he bred in British elite institutions (Eton and then King's College Cambridge). He also became a member of the 'Bloomsbury group', a collection of upper-class Edwardian intellectuals such as Virginia Woolf, Clive Bell and Lytton Strachey, who proved to be great innovators in aesthetic, literary and cultural thought. He revolutionised economics with his General Theory of Employment, Interest and Money $(1936)^{2}$, which is commonly regarded as the most influential economic treatise of the past century, in that it changed the way the world looked at the economy and the role of government in society. The General Theory was immediately and widely successful and it further confirmed Keynes's popularity and intellectual prominence. From the very start, the book caught the attention of economists and was generally accepted as a landmark in economic thought. As Keynes had hoped, the revolutionary significance of his work was soon acknowledged and nowadays many commentators see the publication of The General Theory as something of a Kuhnian revolution. Apart from his innovative academic activity, John Maynard Keynes also performed several important public functions.

The analysis of Keynes's text carried out here - which is mainly of a qualitative type aims to identify what is distinctive about the author's choice of language as opposed to what is part of the collective norms of the disciplinary community he belonged to. By concentrating on those cases in which the author's individual textual choices prevail over the accepted conventions of economic academic discourse I aim to show that, in order to reach his perlocutionary goal, the author has often flouted the conventions of commonality practice and preferred instead to opt for the individuality of personal expository strategies.

\subsection{Subjectivity in the use of terminology}

The General Theory contains various exceptions to the discursive criteria which are commonly followed in specialised communication. One of these exceptions concerns the use of domain-specific terminology. For example, the principle of monoreferentiality is 
frequently violated, as shown by the presence of many cases of ambiguity and polysemy present in the text. This appears to be the result of a deliberate decision, as Keynes clearly asserts that he disagrees with the use of monoreferential language because of its excessive rigidity and inability to describe complex phenomena in an adequate manner. He argues that:

(8) too large a proportion of recent 'mathematical' economics are merely concoctions, as imprecise as the initial assumptions they rest on, which allow the author to lose sight of the complexities and interdependencies of the real world in a maze of pretentious and unhelpful symbols. (GT:298)

Translating thoughts into the precise, unequivocal terms of a symbolic-mathematical language is for Keynes an obstacle to their development, as the continuous conceptual changes of economic reasoning require a more flexible expressive system that allows for constant redefinition of the terms' referents. This inadequacy leads Keynes to view symbolic-mathematical language as a source of confusion and misunderstanding, due not to specialised discourse itself but to the fact that it is used in a non-positivistic discipline such as economics. The need to differentiate between academic disciplines is strongly felt by Keynes, who is convinced that economics should not be classified as a hard science but as a moral science. ${ }^{3}$ On this conception, economic theory loses its dogmatic character and takes persuasion as its only goal.

Another element which has caused ambiguity in Keynes's text is his rather peculiar use of economic terminology. Insofar as the reader has a reasonable expectation that, once a technical term has been introduced in one sense, it will continue to be used in that way until the author should decide otherwise, Keynes's attitude here can be regarded as an infringement of those expectations. Indeed, a close reading of The General Theory shows that terms are not always monoreferential but rather may refer to different concepts. One of these, for example, is investment, which in the course of the book is linked to three different meanings. In spite of the different concepts, Keynes does not feel the need to adopt three terms or to qualify the lexeme investment with different adjectives so as to avoid the danger of ambiguity. Keynes is aware of his ambiguous use of terminology, yet he considers this an essential part of his methodological position: ${ }^{4}$

(9) A definition can often be vague within fairly wide limits and capable of several interpretations differing slightly from one another, and still be perfectly serviceable and free from serious risks [...], provided that [...] it is used consistently within a given context. If an author tries to avoid all vagueness and to be perfectly precise, he will become [...] prolix and pedantic. (CW XXIX:36)

Although he feels that new terms are often a necessity when writing an argumentative text, the defining process is perceived as a constraint to his creativeness and as a con- 
siderable limitation to the decoder's intuitive possibilities. Keynes thus endows his terms with interpretational subjectivity because the extreme variability of their referents is more appropriate to his dynamic view of the economic system.

\subsection{Authorial presence}

Depersonalisation is commonly considered a standard feature of specialised discourse, which is characterised by passivisation and the absence of an explicit agent (Gotti 2008). This approach rests on the assumption that principles and properties are suggested to the scientist by direct observation of phenomena. The inductive process is realised linguistically by reduction of the human element and personalisation of the experiment's physical aspects. This is not a general feature, however, of Keynes's argumentative strategy, as first-person pronouns (usually singular) commonly identify the locutor in order to stress his authorial autonomy within the discipline. Keynes's use of first-person pronouns is particularly frequent and is indicative of the author's great effort to convince readers by emphasising the argumentative structure of his discourse. A clear example of this model is the text below, where the recurrent thematic position of the subject $I$ marks the author's critical stance towards classical theorists and the effort to prove the innovative nature of his work:

(10) I have called this book the General Theory of Employment, Interest and Money. I have placed the emphasis on the prefix general to contrast the character of my arguments and conclusions with those of the classical theory. I have become accustomed, perhaps perpetrating a solecism, to include in 'the classical school' the followers of Ricardo, including (for example) J.S. Mill, Marshall, Edgeworth and Prof. Pigou. I shall argue that the postulates of the classical theory are applicable to a special case only and not to the general case, the situation which it assumes being a limiting point of the possible positions of equilibrium. (GT:3)

The frequent use of first-person subjects enables Keynes to affirm his authorial stance (Biber/Finegan 1989, Hyland 2005) very effectively and to allow his personality to come through very strongly in his writing. Moreover, this personal voice proves to be particularly effective not only to convey the author's confident authoritativeness and well-established renown but also to express his self-assured awareness of the innovativeness of his theoretical proposal.

\subsection{Argumentative strategies}

The General Theory points to a close link between the author's language and his heuristic method, which surfaces especially in his drafting plan. Although he is willing to organise the text according to the theoretical foundations of economics, this relation- 
ship between method and composition seems at times to create major difficulties, especially whenever the drafting pattern clashes with the non-sequential nature of his theoretical argumentation. The conflict derives from the fact that Keynes's analytical model is based on the notion that there is an organic interdependence between economic variables that cannot be adequately accounted for by the atomistic approach typical of classical theory. Keynes explains the systematic nature of his new method at a point in The General Theory where the new methodology is introduced:

(11) The object of our analysis is, not to provide a machine, or method of blind manipulation, which will furnish an infallible answer, but to provide ourselves with an organised and orderly method of thinking out particular problems; and, after we have reached a provisional conclusion, by isolating the complicating factors one by one, we then have to go back on ourselves and allow, as well as we can, for the probable interactions of the factors amongst themselves. (GT:297)

Keynes's heuristic method thus proposes to overcome the restricted confines of classical economics by dealing with two opposing needs. On the one hand, the need to examine economic variables as isolated elements; on the other, the need to draw on independent studies to show the close interrelations among the various variables examined. This alternation between linear atomistic analyses and complex systemic integration is reflected in the expository form of the book. At that level, there are recurrent cross-references to other parts of the book. For Chick this technique resembles the expository language of cinema, as “Keynes's method is more like a film, a moving picture, made from snapshots (as films are), each snapshot systematically related to what has gone before. It is a story full of flashbacks - and flashes forward" (1983:14).

By continually referring the reader to other parts of The General Theory, Keynes balances the complexity and systemic interdependence of the various parts of his analysis with the linear progression of his monograph. This is illustrated by several examples of how Keynes moves away from the text in order to help the reader to grasp the overall scheme of the book. In so doing he signals which aspects of a given economic problem deserve attention in later chapters:

(12) The theory of wages in relation to employment, to which we are here leading up, cannot be fully elucidated, however, until chapter 19 and its Appendix have been reached. (GT:18)

(13) It may be mentioned, in passing, that the effect of fiscal policy on the growth of wealth has been the subject of an important misunderstanding which, however, we cannot discuss adequately without the assistance of the theory of the rate of interest to be given in Book $I V$. (GT:95) 
The frequent presentation of new material combined with reference to previously discussed matters gives Keynes's work its unique character, which is very different from that of the traditional academic essay. Chick finds that The General Theory's expository approach is in many ways similar in structure to a play:

To make clear the structure of the General Theory, it might be helpful to compare the book to a play. When characters go off-stage in the theatre, you do not presume them to be dead - they are likely to pop back at any time. The General Theory is rather like that. Early on (G.T. Chapter 3) you are given a sketch of the plot, but it is only much later (G.T. Chapters 19-21) that the full story is revealed. (Chick 1983:28)

Another central feature is the utility of insights, which allow both reader and writer to perceive aspects which might escape notice using only deductive observational methods. Such insights are important for understanding the text as well as its composition process, as they point to the line of reasoning and also clarify its details and applications. The act of writing is itself part of Keynes's heuristic effort, which allows him to keep ahead by means of chains of intuitions and deductions when uncovering the facts of economic life. This explains his frequent recourse in argumentation to hypothetical clauses preceded by a premise and followed by a conclusion, with an argumentative pattern of the kind: Let (Z) be... Now if..., thus... An alternative variant starts with the observation of some 'facts of experience' or features of 'human nature', from which the author draws his conclusions with expressions such as If this is true, it follows that...

\subsection{Emotional involvement}

A predictable feature of specialised discourse is the high referential value of its texts, combined with limited emotional involvement on the part of readers. In Walton's words:

Traditionally, appeals to emotion in argument have been distrusted and even labeled categorically as logical fallacies. There is a common tendency to contrast 'impartial reason' with 'the passions' and to distrust the latter in reasoned argument. And this tendency is often affirmed in logic texts where appeals to emotion have been treated as inherently illogical and subject to strong censure. (Walton 1989:82-83)

For Keynes, however, this assumption does not seem to hold. He seeks to convince the audience not only through sound demonstration and factual evidence but also using plausible, persuasive argumentation that is not necessarily irrefutable. For this purpose, figurative and emotive language, which is normally considered alien to the epistemology of specialised discourse, is often employed. Indeed, when reading The General Theory one immediately perceives that the conflictual element implicit in all argumentative texts $^{5}$ is here taken to extremes. This impression is confirmed by a reading of Keynes's 
correspondence with colleagues and friends, which reveals his determination to highlight conflictual aspects in The General Theory. In reply to Ralph F. Harrod, he announces that "I want, so to speak, to raise a dust; because it is only out of the controversy that will arise that what I am saying will get understood". (CW XIII:548)

Keynes's decision to 'turn up the volume' (Martin 2000) and adopt a highly conflictual stance is coherently maintained in his writing, as reflected by the harsh, polemic tone which characterizes his use of words and figures of speech, especially in the Preface and in Chapter 12. The choice of lexis demonstrates the author's ability to criticize contemporary economic theory and express new ideas in an extremely figurative, connotative language. Keynes's use of words suggests to readers that his work is conceived as a reaction against current theory, "a long struggle of escape from habitual modes of thought and expression" (GT:xxiii). He has reached a state of freedom from the preconceived doctrines of the past and feels "to be breaking away from this orthodoxy, to be in strong reaction against it, to be escaping from something, to be gaining emancipation." (GT:xxiii). He wants to make a clean break with the past, as the theory prevalent among academics has proved to be "misleading and disastrous" (GT:3).

Chapter 12 is especially representative of Keynes's emotional tone. Its aim is to convince readers of the unreliability of economic decisions concerning investments, due to the level of irrationality in investors' behaviour. To underline the irrational element, Keynes argues "on a different level of abstraction from most of the book" (GT:149), rather than adopting a logical line of reasoning. In particular, he decides to adopt lexical items with a strong emotional load, generally indicating excessive presence or absence of certain traits. The most frequent fields where such excess occurs are reasonableness (foolish, unreasoning, vagaries, irrational), quantity (disproportionately, outstanding, extreme, negligible, scanty, slight, non-significant), size (extensive, enormous, vast), norm (abnormal, anti-social), gravity (disastrous, collapse, serious) and force (violently, prevailing, predominates, predominance). The markedness of Keynes's text is also denoted by the incongruous semantic fields from which many lexical items are taken. Some of those found in Chapter 12 are religion (temptation, orthodox, fetish, doctrine, faith, sins), physical elements (sanguine, instinct, animal spirits) and war (gun, battle, assailed). Even when lexical items do not denote excess or unnaturalness, they are often made more marked by the use of intensifying or attitudinal premodifiers which emphasize certain semantic traits or comment on them. The main of such premodifying expressions in The General Theory are decisively, very, highly, most, seriously, much more, intolerably, over-, entirely and scarcely. On other occasions the author underlines the degree of validity of his assertions by means of attitudinal adverbials such as obviously, surely, indeed, of course, frankly and in truth.

Apart from the linguistic items described above, Keynes makes use of various rhetorical devices to emphasize emotiveness. One of such means is reinforcement, whereby the semantic load of a lexical item is strengthened by a synonym or a related term. Examples include: vague and scanty, very slight and often negligible, ephemeral and non-significant, intolerably boring and over-exacting, inaccessible and very expensive, permanent and indissoluble, supplemented and supported. Sometimes the sequence is extended, 
with the addition of a third element whose function is to increase the effect of the whole string: eccentric, unconventional and rash; disastrous, cumulative and far-reaching repercussions.

A further rhetorical device used by Keynes to make his argumentative text more emotional is metaphor. ${ }^{6}$ What creates the emotional effect is once again the use of lexical items drawn from fields not directly connected to economics; moreover, these all bear strong connotations and are therefore likely to arouse an emotional response in the reader. The commonest are religion (the fetish of liquidity, the sins of the London Stock Exchange), war (dark forces of time and ignorance which envelop our future, this battle of wits, to defeat the forces of time), corporal states (to feed the maws of the professional, gambling instinct), natural states (a steady stream of enterprise, a whirlpool of speculation) and playing games (businessmen play a mixed game, the game of professional investment, gambling instinct). The last of these is the one most frequently employed by Keynes, as it enables him to convey his argument in a most convincing way: by wording his persuasive strategy in emotional rather than rational terms, Keynes selects the analogy INVESTMENT $=$ GAME as the most memorable way to represent the irrationality and unpredictability of long-term investment. His thesis is based on the assumption that investment decisions do not rely merely on objective factors, but are conditioned by subjective elements which cannot always be predicted with absolute certainty and therefore make the whole investment system very unreliable. This line of interpretation is strengthened by the many metaphors related to the semantic field of gambling that occur throughout the text:

(14) the affair was partly a lottery (GT:150)

a mixed game of skill and chance (GT:150)

a game of Snap (GT:155)

a pastime (GT:156)

these games can be played with zest and enjoyment (GT:156)

professional investment may be likened to those newspaper competi-

tions (GT:156)

large profits to be gained from the other players (GT:156)

unperturbed by the prevailing pastime (GT:156)

predominate in their influence over the game-players (GT:156)

the game of professional investment (GT:157)

the gambling instinct (GT:157)

the higher return from the pastime (GT:157)

a by-product of the activities of a casino. (GT:159)

The number of metaphors that recall gambling is so high that their use is clearly the result of the author's choice to evoke in the reader's mind an immediate association between the notion of investment and aspects connected to gambling, such as unpredictability, risk, etc. 


\title{
3.5. Reader involvement
}

It is generally considered inappropriate to seek out aesthetic value in specialised texts because this is not a priority for academic authors. Keynes, however, seems to contradict this general criterion, partly because of influences from the Bloomsbury group to which he belonged, together with such literary figures as Leonard and Virginia Woolf, Lytton Strachey, E.M. Forster, Clive and Vanessa Bell. In The General Theory he shows a keen awareness of the great expressive potential of language and successfully exploits it in his economic argumentation, especially to engage readers in a cooperative effort when interpreting his text. Keynes's own words seems to confirm this hypothesis:

\begin{abstract}
It is, I think, of the essential nature of economic exposition that it gives, not a complete statement, which even if it were possible, would be prolix and complicated to the point of obscurity but a sample statement, so to speak, out of all the things which would be said, intended to suggest to the reader the whole bundle of associated ideas, so that, if he catches the bundle, he will not in the least be confused or impeded by the technical incompleteness of the mere words which the author has written down, taken by themselves. [...] An economic writer requires from his reader much goodwill and intelligence and a large measure of co-operation. (CW XIII:470)
\end{abstract}

In this passage, Keynes interestingly describes the argumentation of economists as a succession of sample statements which work by suggesting to the reader a whole bundle of associated ideas. In this way the text provides readers with cues for personal associations, rather than unambiguous conclusions determined by an orderly set of premises and reasonings. Thus, we can clearly see that even the ambiguity of certain passages of The General Theory is not accidental but due to a deliberate choice on the author's part. Keynes meant this to be an 'open work' (Eco 1989), allowing readers to play an active role in interpreting his new theory bringing the author's creation to fruition. Its final form was meant to be flexible, capable of being read in a variety of ways and open to the critical, interpretative agency of the reader. A year after publication, Keynes offered the following comment:
I am more attached to the comparatively simple fundamental ideas which underlie my theory than to the particular forms in which I have embodied them, and I have no desire that the latter should be crystallised at the pres- ent stage of the debate. If the simple basic ideas can become familiar and acceptable, time and experience and the collaboration of a number of minds will discover the best way of expressing them. (CW XIV:111)

As Keynes himself admits, the reader is asked to offer not just the usual sort of cooperation, but a much higher level of intuitive involvement and goodwill. The General Theory is therefore one of the few non-literary texts whose author, willingly and know- 
ingly, assigns to readers not merely the role of decoders and recipients of his views but a far more demanding role as his collaborators in working out of the final form and the exact meaning of a new economic theory.

\section{Conclusion}

The two case studies analysed in this paper have enabled us to explore the complex and dynamic relationships existing between shared disciplinary norms and individual traits in academic writing so as to promote a comprehensive understanding of the interactions between discursive practices and their contextual constraints and localisations. By investigating authorial identity as an aspect of discourse performance in the published work of two leading figures it has been possible to show how academics holding a high status in their disciplines manage the tension between commonality and individuality, contributing either to the establishment of shared communicative norms or the assertion of innovative discursive practices.

The analysis presented here suggests that these two experienced writers exploit the rhetorical elements available in their language in very different ways and make contrasting choices to argue their ideas and engage with their readers. Robert Boyle interprets the needs of his community of practice and by means of specific metatextual indications and practical exemplifications contributes to the outlining of the new stylistic approach envisaged by the specialised discourse writers of his time. Through his reflections and writing practices he thus played a seminal role in the formation of the discursive conventions not only of the community he belonged to but also of future generations of scholars as his views and practices were widely adopted in the world of specialised research and argumentation.

John Maynard Keynes, instead, willingly challenged the existing discursive conventions to construct a more assertive identity. Indeed he did not always shape his arguments in a way that would meet the standard expectations of his readership or of the economic community in general, as he violated the more predictable features of economics argumentative discourse. Also the importance that he attributes to the use of a metaphorical language in economic argumentation derives from his epistemological beliefs that the success of a theory relies on its being accepted by its addressees rather than on objective evidence or explicit proof. This emphasis on the perlocutionary aim of his writing also explains the author's marked preference for the explicit use of the first person, which betrays Keynes's willingness to enhance the persuasive force of his argumentation by endowing his rhetoric with the subjectivity of his personal convictions. This choice proved to be wise, as the great success of this work was due not only to the author's insightful understanding of the real causes of economic phenomena and his original proposal of appropriate measures to be taken, but also to the great effectiveness of his persuasive argumentation.

The very personal and creative use of argumentative discourse made by Keynes has shown that, while often seen as normative and constraining, the rhetorical conventions of academic communities are also the raw materials from which scholars - selecting and 
using the rhetorical repertoire available - fashion their professional selves and affirm their individual identities. The personal solutions observed in his text have provided valuable evidence of individual proclivities in the choice of linguistic items and the use of particular argumentative strategies. A recognition of the conscious decisions taken by this academic writer thus confirms that textual differences cannot merely be interpreted in terms of standard vs. non-standard options, but are clearly a result of the deliberate strategic (and often creative) avenues explored by authors in view of their rhetorical objectives, and reflect the considerable challenges and opportunities that confront scholars seeking to balance the delicate relationship between commonality and individuality in academic communication.

\section{Notes:}

1. This paper was first presented as a plenary lecture at the 10th Conference of the European Society for the Study of English, held in Torino (Italy) on 24-28 August 2010. The research on which this chapter is based is part of the National Research Programme Tension and Change in Domain-specific Genres directed by prof. Maurizio Gotti of the University of Bergamo (Italy), funded by the Italian Ministry of University (COFIN Grant No. 2007JCY9Y9).

2. The General Theory of Employment, Interest, and Money (London: Macmillan, 1936, henceforth GT) is cited here from The Collected Writings of John Maynard Keyes (Vol. VII, London: Macmillan, 1973), whose various volumes are referred to by the initials $\mathrm{CW}$.

3. The 'objectivity' of scientific research is a concept that has been questioned by several scholars in recent years (cf. Bazerman 1984; Myers 1990; Hunston / Thompson 2000).

4. For an examination of Keynes's economic method see Carabelli (1988). For an analysis of his writing method see Marzola/Silva (1994), and in particular the chapter by Gotti.

5. The presence of conflictual aspects in argumentative discourse has been pointed out in several studies: among others, Salager-Meyer (2000), Salager-Meyer/Zambrano (2001), Gotti et al. (2002).

6. For MacCormac: "metaphor results from a cognitive process that juxtaposes two or more not normally associated referents, producing semantic conceptual anomaly, the symptom of which is usually emotional tension" (1985:5). The importance of the use of a metaphorical language in economic argumentation has recently been pointed out even by economists themselves; see, for example, McCloskey: "When an economist says, as she frequently does, 'the demand curve slopes down', she is using the English language; and if she is using it to persuade, as she very frequently is, she is a rhetor [...], whether she knows or likes it or not." (McCloskey 1998:23). On the use of metaphor in economic academic writing, see, among others, Richardt (2005:147-158). 


\section{References:}

1. Atkinson, D. (1999) Scientific Discourse in Sociohistorical Context: The Philosophical Transactions of the Royal Society of London, 1675-1875. Mahwah, N.J.: Lawrence Erlbaum.

2. Bakhtin, M. (1986) Speech Genres and Other Late Essays. Austin: University of Texas Press.

3. Bazerman, C. (1984) Modern Evolution of the Experimental Report in Physics: Spectroscopic Articles in Physical Review, 1893-1980. // Social Studies of Science. Vol.14, 163-196.

4. Bhatia, V.K. (1993) Analysing Genre: Language Use in Professional Settings. London: Longman.

5. Bhatia, V.K. (2004) Worlds of Written Discourse: A Genre-based View. London: Continuum.

6. Bhatia, V., Gotti, M. (Eds) (2006) Explorations in Specialized Genres. Bern: Peter Lang.

7. Biber, D., Finegan, E. (1989) Styles of Stance in English: Lexical and Grammatical Marking of Evidentiality and Affect. // Text. Vol. 9(1), 93-124.

8. Boas Hall, M. (1965) Robert Boyle on Natural Philosophy. Bloomington: Indiana University Press.

9. Boas Hall, M. (1991) Promoting Experimental Learning: Experiment and the Royal Society 1660-1727. Cambridge: Cambridge University Press.

10. Boyle, R. (1772) The Works. / Ed. by Thomas Birch. 6 vols. London: J. \& F. Rivington; rpt. Hildesheim: G. Olm, 1965.

11. Carabelli, A.M. (1988) On Keynes's Method. London: Macmillan.

12. Chafe, W., Nichols, J. (Eds) (1986) Evidentiality: The Linguistic Coding of Epistemology. Norwood: Ablex.

13. Cherry, R.D. (1988) Ethos versus Persona: Self-representation in Written Discourse. // Written Communication. Vol. 5(3), 251-276.

14. Chick, V. (1983) Macroeconomics after Keynes. Oxford: Philip Allan.

15. Crammond, J. (1998). The Uses and Complexity of Argument Structures in Expert and Student Persuasive Writing. // Written Communication. Vol.15(2), 230-268.

16. Eco, U. (1989) The Open Work. Cambridge, MA: Harvard University Press.

17. Gotti, M. ('2005, $\left.{ }^{2} 2008\right)$ Investigating Specialized Discourse. Bern: Peter Lang.

18. Gotti, M., Heller, D., Dossena, M. (Eds) (2002) Conflict and Negotiation in Specialized Texts. Bern: Peter Lang.

19. Hatch, J.A., Hill, C.A., Hayes, J.R. (1993) When the Messenger is the Message. // Written Communication. Vol.10(4), 569-598.

20. Hunston, S. Thompson, G. (Eds) (2000) Evaluation in Text: Authorial Stance and the Construction of Discourse. Oxford: Oxford University Press.

21. Hunter, M. (1989) Establishing the New Science: The Experience of the Early Royal Society. Woodbridge: Boydell Press.

22. Hyland, K. (2000) Disciplinary Discourses. Social Interactions in Academic Writing. London: Longman. 
23. Hyland, K. (2005) Metadiscourse. London: Continuum.

24. Ivanič, R. (1998) Writing and Identity: The Discoursal Construction of Identity in Academic Writing. Amsterdam: Benjamins.

25. Jardine, L. (1999) Ingenious Pursuits: Building the Scientific Revolution. London: Little / Brown.

26. Keynes, J.M. (1973) The Collected Writings of John Maynard Keyes. London: Macmillan.

27. Lave, J. / Wenger, E. (1991) Situated Learning: Legitimate Peripheral Participation. Cambridge: Cambridge University Press.

28. MacCormac, E.R. (1985) A Cognitive Theory of Metaphor. Cambridge, MA: The Massachusetts Institute of Technology Press.

29. Martin, J.R. (2000) Beyond Exchange: APPRAISAL Systems in English. // In Hunston/Thompson (eds), 142-175.

30. Marzola, A.; Silva, F. (eds) (1994) John Maynard Keynes: Language and Method. Aldershot: Edward Elgar.

31. McCloskey, D. $\left({ }^{1} 1985,{ }^{2} 1998\right)$ The Rhetoric of Economics. Madison: University of Wisconsin Press.

32. Myers, G. (1990) Writing Biology: Texts in the Social Construction of Scientific Knowledge. Madison: University of Wisconsin Press.

33. Richardt, S. (2005) Metaphor in Languages for Special Purposes. Frankfurt am Main: Peter Lang.

34. Salager-Meyer, F. (2000) Rhetorical Evolution of Oppositional Discourse in French Academic Writing. // Hermés / vol.25, 23-48.

35. Salager-Meyer, F. / Zambrano, N. (2001) The Discourse of Competing Knowledge Claims in Academic Prose. // Language for Special Purposes: Perspectives for the New Millennium. / Ed. by Felix Mayer (ed.), Tübingen: Narr, 474-479.

36. Shapiro, B. (2000) A Culture of Fact: England, 1550-1720. Ithaca: Cornell University Press.

37. Sprat, T. (1667) A History of the Royal Society of London for the Improving of Natural Science. London: Martyn; rpt. London: Routledge \& Kegan Paul, 1959.

38. Swales, J. (1990) Genre Analysis. English in Academic and Research Settings. Cambridge: Cambridge University Press.

39. Swales, J. (1998). Other Floors, Other Voices. A Textography of a Small University Building. Mahwah, NJ: Earlbaum.

40. Swales, J. (2004) Research Genres: Explorations and Applications. Cambridge: Cambridge University Press.

41. Taavitsainen, I. (2001) Evidentiality and Scientific Thought-Styles: English Medical Writing in Late Middle English and Early Modern English. // Modality in Specialized Texts. / Ed. by Maurizio Gotti / Marina Dossena, Bern: Peter Lang, 2152.

42. Vickers, B. (ed.) (1987) English Science: Bacon to Newton. Cambridge: Cambridge University Press.

43. Walton, D.N. (1989) Informal Logic. Cambridge: Cambridge University Press. 


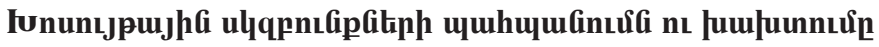 qhunulyufi qpulqufinıpjufi út,}

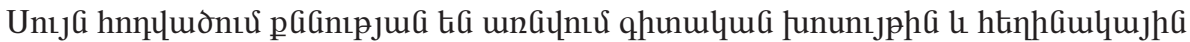

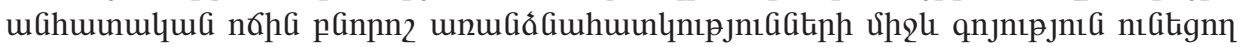

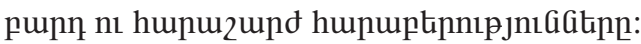

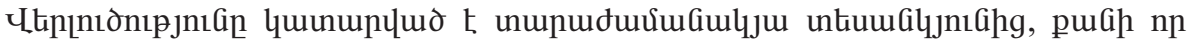

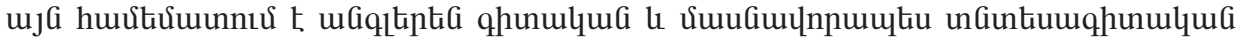

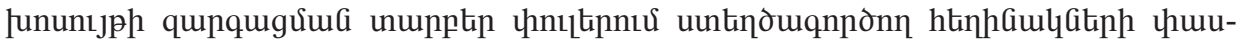
unuplưua n夭tipn:

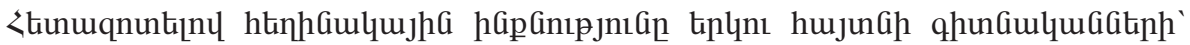

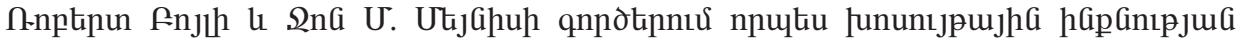

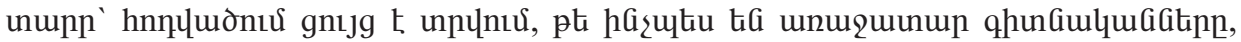

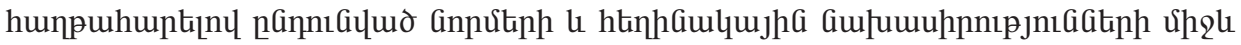

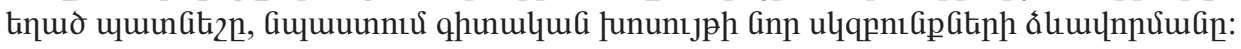

